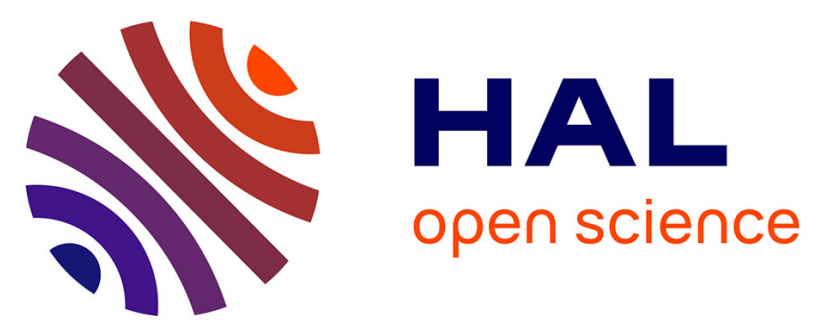

\title{
Relation between structure and ions mobility in polypyrrole electrosynthesized under high frequency ultrasound irradiation
}

\author{
A. Et Taouil, F. Lallemand, J.-Y. Hihn, L. Hallez, V. Moutarlier, V.
} Blondeau-Patissier

\section{To cite this version:}

A. Et Taouil, F. Lallemand, J.-Y. Hihn, L. Hallez, V. Moutarlier, et al.. Relation between structure and ions mobility in polypyrrole electrosynthesized under high frequency ultrasound irradiation. Electrochimica Acta, 2011, 58, pp.67-75. 10.1016/j.electacta.2011.08.087 . hal-00678458

\section{HAL Id: hal-00678458 https://hal.science/hal-00678458}

Submitted on 30 Apr 2021

HAL is a multi-disciplinary open access archive for the deposit and dissemination of scientific research documents, whether they are published or not. The documents may come from teaching and research institutions in France or abroad, or from public or private research centers.
L'archive ouverte pluridisciplinaire HAL, est destinée au dépôt et à la diffusion de documents scientifiques de niveau recherche, publiés ou non, émanant des établissements d'enseignement et de recherche français ou étrangers, des laboratoires publics ou privés.

\section{(c)(1)}

Distributed under a Creative Commons Attribution| 4.0 International License 


\title{
Relation between structure and ions mobility in polypyrrole electrosynthesized under high frequency ultrasound irradiation
}

\author{
Abdeslam Et Taouil a,1, Fabrice Lallemand ${ }^{\mathrm{a}, *, 1}$, Jean-Yves Hihn ${ }^{\mathrm{a}, 1}$, Loïc Hallez ${ }^{\mathrm{a}}$, Virginie Moutarlier $^{\mathrm{a}}$, \\ Virginie Blondeau-Patissier ${ }^{\mathrm{b}}$ \\ a Institut UTINAM, UMR 6213 CNRS, Université de Franche-Comté, 30 Avenue de l'observatoire, 25009 Besançon, Cedex, France \\ b FEMTO-ST, UMR 6174 CNRS, Université de Franche-Comté, 26, Chemin de l'Epitaphe, 25030 Besançon, Cedex, France
}

High frequency ultrasound $(500 \mathrm{kHz})$ was shown to have very interesting effects on PPy elaborated with various counter-ions: perchlorate ( $\left.\mathrm{ClO}_{4}{ }^{-}\right)$, $\mathrm{p}-$ toluenesulfonate $\left(\mathrm{TS}^{-}\right)$and molybdate $\left(\mathrm{MoO}_{4}{ }^{2-}\right)$. Changes in polymer growth for sonicated films were highlighted by Atomic Force Microscopy (AFM) while Scanning Electron Microscopy (SEM) showed thinner and more homogeneous surface structure for PPy elaborated under ultrasound. Mobility of ions within PPy films was studied by electrochemical techniques, sonicated PPy seems to have much denser and more compact structure than silent one's. Specific electrochemical behavior was evidenced for sonicated $\mathrm{PPy} / \mathrm{MoO}_{4}{ }^{2-}$ as well as unique ions reparation within the organic matrix, thanks to Glow Discharge Optical Emission Spectroscopy (GDOES). This technique was used in original manner to study presence and repartition of doping ions in the film. X-Ray Photoelectron Spec-troscopy (XPS) analyses showed an increase in doping level for sonicated PPy but electrical conductivity measurements let appear a decrease in conductivity for PPy elaborated under sonication.

\section{Introduction}

Materials such as conducting polymers (CPs), which combine polymer properties to good electrical conductivity, have been extensively investigated for the last 30 years. It led them to be used in many various applications like field effect transistors [1,2], lightemitting diodes [3], solar cells [4,5], protection of metals [6,7] or biosensors [8-10] to name a few. The easiness of preparation and the possibility to control experimental conditions by electrochemical technique make it the most employed way. Polypyrrole (PPy) stays one of the most studied CPs, particularly due to its easy deposition from aqueous and non-aqueous media, to its adherence to many types of substrates, its conductivity and stability. Chemical and physical properties of electrochemically deposited PPy have been shown to be strongly dependent on many parameters: the nature of solvent, the supporting electrolyte, the temperature, the deposition potential/current $[11,12]$.

Several original techniques have been employed during electrosynthesis in order to influence CPs properties. Use of magnetic field $[13,14]$ or centrifugation [15] leads to changes in structural and electrochemical properties of polymer deposits. Among these

\footnotetext{
* Corresponding author. Tel.: +33 3816668 56; fax: +33 381666858 .

E-mail address: fabrice.lallemand@univ-fcomte.fr (F. Lallemand).

1 ISE member.
}

techniques, the use of ultrasound has been studied. Indeed, propagation of a power ultrasound wave through a liquid medium induces strong mechanical, physical and chemical changes leading to activation of chemical or electrochemical reactions [16,17]. Acoustic cavitation is predominant causing collapse of cavitation bubbles and generation of large pulses of stress, followed by a high velocity fluid jet. When occurring on the electrode surface, micro-jets are responsible for mass transfer enhancement [18], impingement attack and erosion by micro streaming. In the liquid bulk, this pulse of stress generates active radical species [19]. Ultrasound showed interesting effects on electropolymerization and on properties of synthesized CPs. Previous works showed that low frequency ultrasound $(20 \mathrm{kHz})$ leads to denser, more resistant and conducting polymer films, with a thinner and more homogeneous surface structure [20-23]. Much bigger compactness has also been reported by Atobe et al. for PPy films leading to very specific electrochemical behavior [24]. Nevertheless, at low frequencies, cavitation phenomena can be very violent leading to partial destruction of the electrodeposited polymer film [25]. At higher frequencies, the behavior of cavitation bubbles is more stable [26] and their destructive effect towards the polymer surface can be highly reduced. In previous works, we showed that high frequency ultrasound leads to thinner and more homogeneous surface structure for PEDOT and PPy films elaborated on various substrates [27-30]. A higher doping level was also observed. It strongly depended on the used substrate and the films' thickness. 
This present contribution means to deeper study the effects of high frequency ultrasound on PPy electrodeposition. First stages of polymer growth and thick deposits are investigated by AFM and SEM imaging. Mobility of ions in the films is also investigated using different sized salts $\left(\mathrm{LiClO}_{4}, \mathrm{NaTS}\right.$, and $\left.\mathrm{Na}_{2} \mathrm{MoO}_{4}\right)$. These results are correlated to bulk structure of the films. Repartition of ions within the organic matrix of $\mathrm{PPy} / \mathrm{MoO}_{4}{ }^{2-}$ is observed by Glow Discharge Optical Emission Spectroscopy (GDOES) and electrochemical behavior for such films is analyzed. Finally, doping levels and electrical conductivities of PPy doped with different counter-ions are evaluated and results are discussed.

\section{Experimental}

\subsection{Chemicals}

Pyrrole monomer (ACROS, $\geq 99 \%, 109-97-7$ ) was distilled at $10 \mathrm{mmHg}$ before use. De-ionized water (solvent) is distilled twice before use (Milli-Q, resistivity $18 \mathrm{M} \Omega / \mathrm{cm}$ ). All other chemicals were purchased from ACROS (analytical grade) and used as received without further purification.

\subsection{Pretreatment of the working electrodes}

Circular-shaped FTO (Fluorine Tin Oxide) substrates $\left(0.38 \mathrm{~cm}^{2}\right)$ were cleaned in a sonication bath, first with dichloromethane $(10 \mathrm{~min})$, then with acetone $(10 \mathrm{~min})$ and finally with water $(10 \mathrm{~min})$. The substrates were then immersed in a water $/ 30 \%$ $\mathrm{H}_{2} \mathrm{O}_{2} / 25 \% \mathrm{NH}_{3}$ mixture $(5: 1: 1, \mathrm{v} / \mathrm{v})$ for $1 \mathrm{~h}$ at $70^{\circ} \mathrm{C}$. Finally, FTO plates were rinsed with copious amounts of ultra-pure water and dried under argon flow.

For chronoamperometry experiments, circular rotating platinum electrode $\left(0.8 \mathrm{~mm}^{2}\right)$ was mechanically polished to mirror finish using diamond suspension of decreasing size, down to $1 \mu \mathrm{m}$ and then rinsed with ethanol.

\subsection{Sonoreactor}

All experiments were performed at an ultrasonic frequency of $500 \mathrm{kHz}$ with an electrical provided power of $25 \mathrm{~W}$, in a $750 \mathrm{ml}$ cell. Ultrasound is produced parallel to the liquid surface, face to face with the working electrode surface. The high frequency transducers used in this work were developed by the Laboratory of Molecular and Environmental Chemistry (University of Savoie, Chambéry, France). The circular transducers consist of a piezoelectric ceramic fixed on a circular plate $(56 \mathrm{~mm})$ made of glass. The multifrequency generator is supplied by Electronic Service (St. Alban Leysse, France). An electronic circuit consisting of a variable inductance and capacitor allows the adjustment between the generator impedance and the strongly capacitive transducer impedance.

The used sonoreactor was characterized in previous work $[27,28]$ by mass transfer measurements and luminol sonochemiluminescence. It was shown that for $500 \mathrm{kHz} 25 \mathrm{~W}$ irradiation, mass transfer coefficient was equal to $4.6 \times 10^{-5} \mathrm{~m} \mathrm{~s}^{-1}$ which corresponds to stirring conditions of $950 \mathrm{rpm}$ rotating electrode. Sonochemiluminescence imaging of luminol revealed big concentration of ultrasound activity at the interface solution/air where the substrate is placed. Ultrasound being used as an external source of energy, evaluation of the corresponding energy conditions within the propagating medium is necessary. Calorimetry measurements are based on the assumption that the acoustic energy is entirely converted into heat during wave propagation. Effective power can be determined by monitoring the temperature increase of a known mass of water versus sonication time [26]. In our case, for a supplied power of $25 \mathrm{~W}$, the transmitted power was found to be $8 \mathrm{~W} \pm 0.5 \mathrm{~W}$, giving an electroacoustic yield of $32 \% \pm 2 \%$. About power density at the electrode surface, it can be calculated as follows: the input power $(25 \mathrm{~W}) \times$ yield $(0.32)$ divided by the transducer surface $\left(12.5 \mathrm{~cm}^{2}\right)$, giving a value of $0.64 \mathrm{~W} \mathrm{~cm}^{-2}$.

\subsection{Electrochemical experiments}

Electrochemical measurements were carried out using a PGZ301 potentiostat and a classical three-electrode setup consisting of a saturated calomel reference electrode (SCE), a platinum counterelectrode and a Fluorine Tin Oxide (FTO) working electrode on which polypyrrole is deposited. The working electrode is placed in the ultrasonic field at the solution/air interface at a distance of $80 \mathrm{~mm}$ from the counter-electrode. The solvent is water and the concentrations are chosen as $0.1 \mathrm{M}$ in pyrrole, $0.1 \mathrm{M}$ in $\mathrm{LiClO}_{4}$ and $0.1 \mathrm{M}$ in NaTS. PPy is deposited at a constant potential of $1 \mathrm{~V} / \mathrm{SCE}$. PPy $/ \mathrm{MoO}_{4}{ }^{2-}$ is deposited from $\left(0.2 \mathrm{M} \mathrm{Py}+5 \mathrm{mM} \mathrm{Na}_{2} \mathrm{MoO}_{4}\right)$ aqueous solution at $1.5 \mathrm{~V} / \mathrm{SCE}$, no deposit was possible below this potential.

\subsection{Deposits characterization}

The polymer surface is characterized by Scanning Electron Microscopy (SEM, JEOL 5600) and by Atomic Force Microscopy (AFM, Molecular Imaging, USA) in contact mode with gold coated $\mathrm{Si}_{3} \mathrm{~N}_{4}$ tip; to observe surface morphology. X-ray Photoelectron Spectroscopy (XPS, Thermo VG spectrometer) is used to control elemental composition and to determine the oxidation state of elements. All spectra were recorded at a $45^{\circ}$ take-off angle, relative to the substrate with a spectrometer using monochromatized $\mathrm{Al}$ $\mathrm{K} \alpha$ radiation $(1486.6 \mathrm{eV})$. The binding energies of the core-levels were calibrated against the C1s binding energy set at $285.0 \mathrm{eV}$, an energy characteristic of alkyl moieties. The peaks were analyzed using mixed Gaussian-Lorentzian curves (80\% of Gaussian character). Glow Discharge Optical Emission Spectroscopy (GDOES) is used to characterize PPy coatings using a Horiba JobinYvon GD Profiler. The coatings were placed as cathode and were sputtered in an argon atmosphere by applying $15 \mathrm{~W}$ under $400 \mathrm{~Pa}$. Electrical conductivity of PPy films was measured using conventional four-probe technique with microohmeter OM 21.

\section{Results and discussion}

\subsection{Growing of PPy films}

Surface morphology was studied for $\mathrm{PPy} / \mathrm{ClO}_{4}{ }^{-}$of different thickness ranging from $5 \mathrm{~nm}$ to $10 \mu \mathrm{m}$. These thicknesses were evaluated using classical Faraday's law assuming $2.25 \mathrm{e}^{-} /$monomer [31,32], a density of $1.5 \mathrm{~g} \mathrm{~cm}^{-3}$ [33,34] and an efficiency of $100 \%$. Polymerization charges are $2.5 \mathrm{mC} / \mathrm{cm}^{2}, 25 \mathrm{mC} / \mathrm{cm}^{2}, 500 \mathrm{mC} / \mathrm{cm}^{2}$ and $5 \mathrm{C} / \mathrm{cm}^{2}$ for evaluated thicknesses of $5 \mathrm{~nm}, 50 \mathrm{~nm}, 1 \mu \mathrm{m}$ and $10 \mu \mathrm{m}$, respectively. AFM was used for very thin deposits $\left(<25 \mathrm{mC} / \mathrm{cm}^{2}\right)$, SEM was employed for deposits with thicknesses superior to $1 \mu \mathrm{m}\left(>500 \mathrm{mC} / \mathrm{cm}^{2}\right)$.

Fig. 1 shows AFM images for PPy deposits of $2.5 \mathrm{mC} / \mathrm{cm}^{2}$ and $25 \mathrm{mC} / \mathrm{cm}^{2}$, with and without ultrasound irradiation. At $2.5 \mathrm{mC} / \mathrm{cm}^{2}$, one can see PPy growth centers over the surface. As shown, when ultrasound is used, their size is decreased and their number increased. A more homogeneous repartition all over the surface is also visible. This may be due to the collapse and implosion of cavitation bubbles generating fluid micro-jets directed towards the surface leading to bigger number of nuclei at the first stages of growing. That would eventually lead to smoother surfaces presenting smaller globules. This theory was already assumed by different authors [35,36]. Moreover, the sound wave may also be the cause for size diminution of pyrrole aggregates 


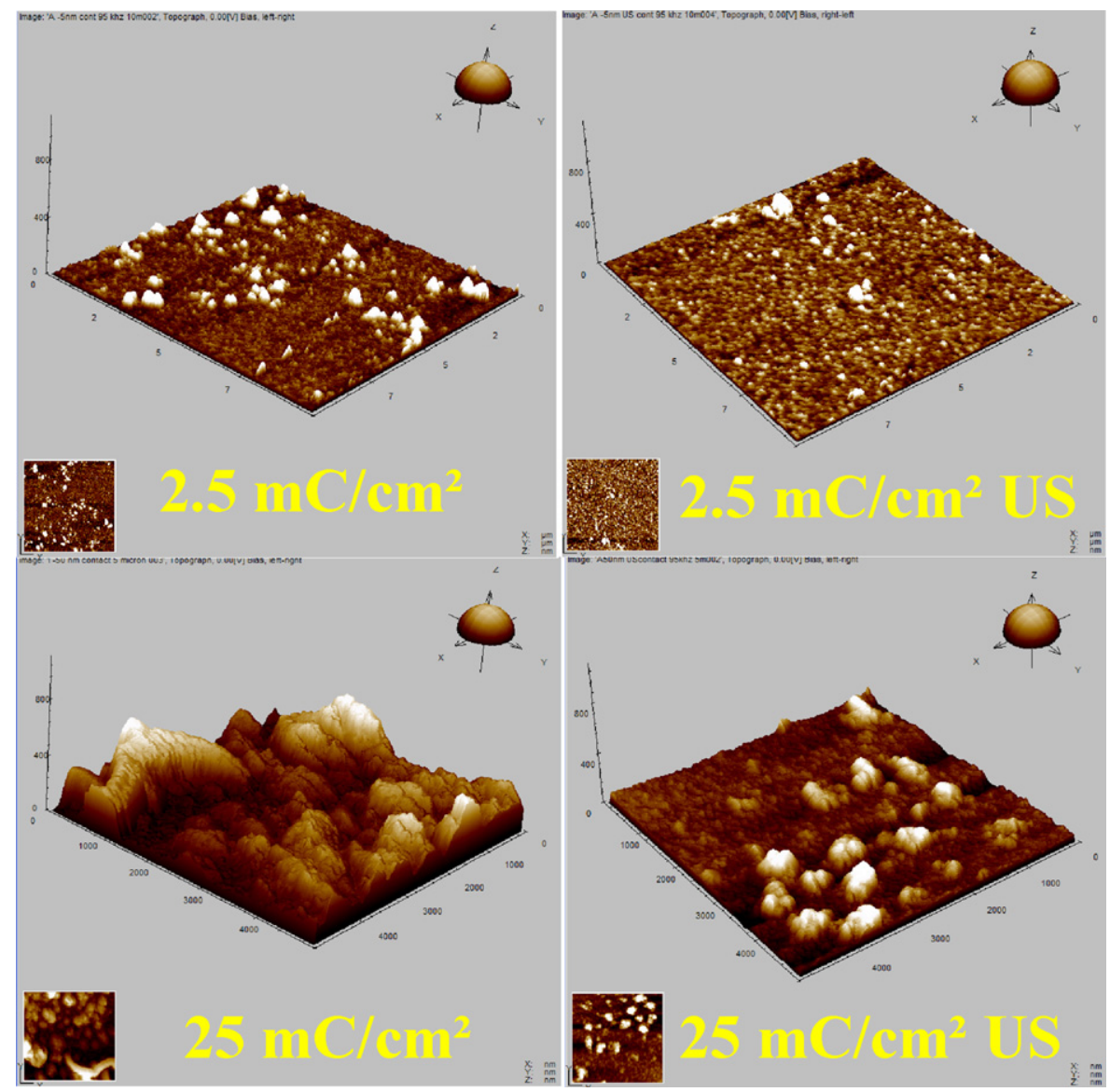

Fig. 1. AFM images (contact mode) of silent and sonicated $\mathrm{PPy} / \mathrm{ClO}_{4}{ }^{-}$for different charge depositions: $2.5 \mathrm{mC} / \mathrm{cm}^{2}$ and $25 \mathrm{mC} / \mathrm{cm}^{2}$.

in solution which would also increase the number of growth centers during polymer expansion. Indeed, ultrasound was employed to homogenize and improve solubility of different organic compounds, especially for electropolymerization [37-39]. We tried to evaluate the size of these pyrrole aggregates in solution by optical counting methods, in order to observe experimentally this presumed size decrease under ultrasound, but the results were not concluding probably due to sizes below the apparatus detection threshold. This change in nucleation-growth leads to surface refining for thicker layers as seen for $25 \mathrm{mC} / \mathrm{cm}^{2}$ deposits. Indeed, the deposit is much thinner under ultrasound and it also seems more compact. In silent conditions, a typical rough mountain-like structure is visible while under sonication the globules are tighter to each other and the structure is much less rough.

Fig. 2 shows SEM images of $500 \mathrm{mC} / \mathrm{cm}^{2}$ and $5 \mathrm{C} / \mathrm{cm}^{2}$ deposition charged $\mathrm{PPy} / \mathrm{ClO}_{4}{ }^{-}$obtained with and without ultrasound irradiation. In all cases, a typical nodular structure is observed. Nevertheless, for silent $5 \mathrm{C} / \mathrm{cm}^{2}$ deposit the morphology tends to be more "hairy-like" with tubular structure starting to grow. Under ultrasound, the sample does not present this type of morphology but seems much more compact. The films obtained under ultrasonication still present thinner and more homogeneous surface structure. Such effects on surface morphology for thick deposits have already been noticed in previous works related to electropolymerization under ultrasound $[20-24,27,28,30]$ and could be useful for applications in which surface structure plays a major role, such as sensing or corrosion protection of CPs.

Same trends were observed for $\mathrm{PPy} / \mathrm{TS}^{-}$(images not shown) when comparing ultrasound and silent conditions. The differences were even more marked for thick deposits ( $>1 \mu \mathrm{m})$.

\subsection{Mass transfer enhancement by ultrasound during chronoamperometry deposition}

$\mathrm{PPy} / \mathrm{ClO}_{4}{ }^{-}$films were grown for $100 \mathrm{~s}$ at $1 \mathrm{~V} / \mathrm{SCE}$ on platinum electrode. Chronoamperometry curves are presented in Fig. 3. The experiment was made in silent conditions, under ultrasound and on $950 \mathrm{rpm}$ rotating electrode in order to work at equivalent transfer coefficient than under ultrasound irradiation as calibrated by mass transfer measurements in previous works [27]. In silent conditions, the curve is typical. An increase is first observed due to creation of active centers. Current density reaches a maximum value after a few seconds and then decreases rapidly. This has been attributed to film overoxidation slowing electropolymerization [11]. Other authors claimed it is due to overlapping of polymer growth centers [40]. Under sonication and rotation, current density does not decrease but stays relatively constant after a quick increase during the first seconds. This behavior is explained by global convection which greatly improves mass transfer of pyrrole monomers to the electrode and thus favors electropolymerization. Nevertheless, even though stirring conditions are the same, current density is higher under ultrasound than under rotating conditions. This behavior has already been noticed in previous study during PEDOT electropolymerization [27] and is also true for PPy/TS ${ }^{-}$(curve not shown). Therefore, it is independent from the studied polymer or the doping anion. It confirms the fact that ultrasound does not only have stirring effects during electropolymerization but other phenomena are present. Transport conditions under ultrasound irradiation and rotating disk electrode must have some similarity for monomers, but interactions of the sound wave with neutral and charged intermediates (for example oligomers, radical cations etc.) could be present, inducing changes in polymerization reaction 

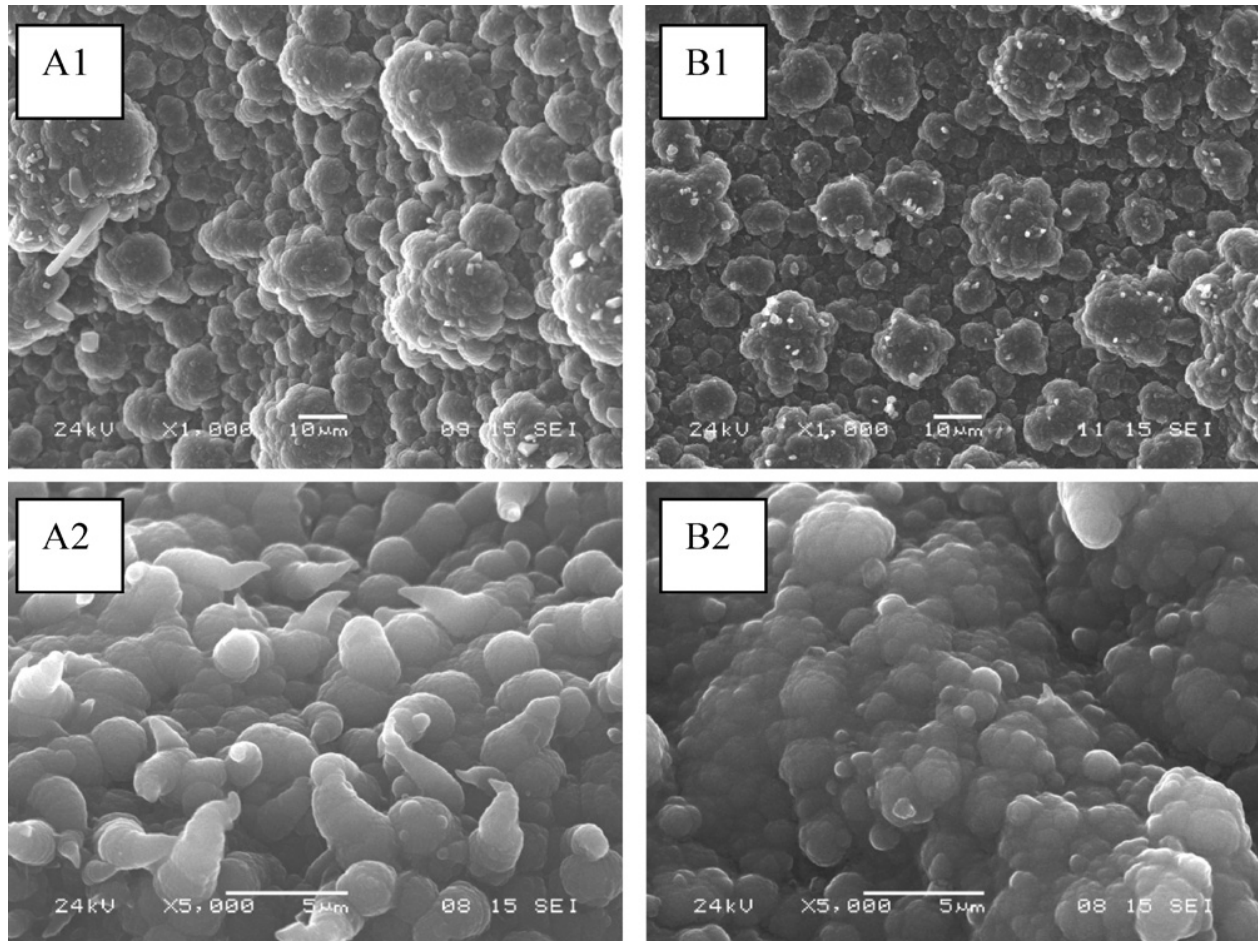

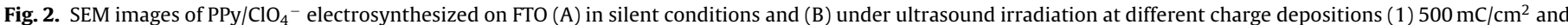
(2) $5 \mathrm{C} / \mathrm{cm}^{2}$

which would explain different current densities observed under sonication. However, no experimental work can support this theory for the moment. Complementary studies are under considerations.

\subsection{Mobility of ions within PPy matrix}

Doping and undoping properties of CPs are of first importance for various applications [24 and references therein]. They assume oxidation and reduction of the film accompanied with diffusion of ions to ensure electroneutrality. The limiting process can either be charge transfer or doping ions diffusion.

A good way to investigate diffusion of ions in PPy films is to compare current densities of the polymer redox peaks observed during voltametry cycling in function of applied scan rates $[11,41,42]$. It has been pointed out by microgravimetric and optical beam deflection measurements [43-45] that cathodic peaks are more suitable for study of counter-ions diffusion in the films as cations easily take part of the charge compensation process at anodic scans, even in the presence of small mobile counter-anions, especially at high anodic potentials.

PPy has been synthesized at $1 \mathrm{~V} / \mathrm{SCE}$ in aqueous solution of $0.1 \mathrm{M}$ $\mathrm{Py}+0.1 \mathrm{M} \mathrm{LiClO}_{4}$ or NaTS with and without ultrasound irradiation at a thickness of $10 \mu \mathrm{m}$. Such big thickness has been chosen to facilitate the study by making ions move deep into polymer bulk. PPy films were then immersed in the same solution without monomer and cyclic voltametry (CV) curves were recorded. Electroactivity of $\mathrm{PPy} / \mathrm{ClO}_{4}{ }^{-}$and $\mathrm{PPy} / \mathrm{TS}^{-}$is showed by reporting obtained CV curves on Fig. 4. Electrochemical dedoping of the films was carried out in such monomer free solution at different scan rates $v$. Peak current densities of the cathodic scan $\left(j_{p, c}\right)$ are plotted versus $v$ and $\sqrt{v}$. The curves and correlation coefficient $R^{2}$ are presented in Fig. 5 for $\mathrm{PPy} / \mathrm{ClO}_{4}{ }^{-}$and Fig. 6 for PPy $/ \mathrm{TS}^{-}$. For these measurements, only the first cathodic peak was considered as afterwards the film is irreversibly altered because of diffusion of (solvated) ions in or out of the film which changed its primary structure. Therefore, subsequent reduction peaks differ from this first one. The reasons of such behavior were largely discussed in the literature, especially in the case of $\mathrm{PPy} / \mathrm{ClO}_{4}{ }^{-}[46]$.

For $\mathrm{PPy} / \mathrm{ClO}_{4}^{-}$(Fig. 5), in silent conditions dependence of $j_{p, c}$ on $v$ is described by a straight line with a correlation coefficient $R^{2}$ of 0.999 while for the plots against square root of $v$, the relation is not so linear $\left(R^{2}=0.9694\right)$. Thus, it seems that limitation of reduction of such $\mathrm{PPy} / \mathrm{ClO}_{4}{ }^{-}$is due to charge transfer. It is not often the case for PPy films but with good mobility of perchlorate anions within the film and with the observed porous structure, diffusion of ions is facilitated. It was also observed for other authors for similar PPy $/ \mathrm{ClO}_{4}{ }^{-}$films $[11,41]$. On the opposite, for sonicated films the relation between $j_{p, c}$ and $\sqrt{v}$ is well linear $(0.9974)$. It seems that diffusion of ions is more difficult in such films. PPy chemical structure being unchanged with ultrasonication as observed by spectroscopic

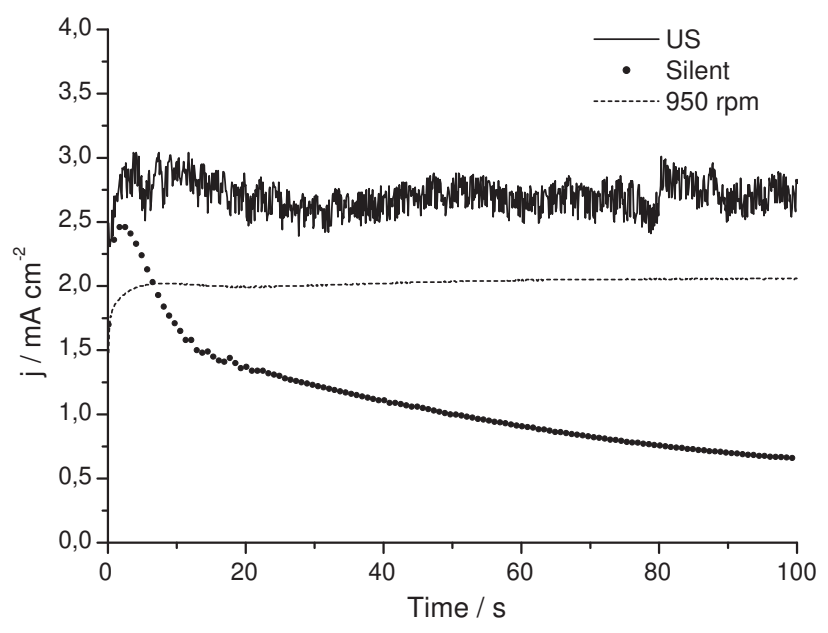

Fig. 3. Chronoamperometry curve of $\mathrm{PPy} / \mathrm{ClO}_{4}{ }^{-}$electrosynthesis in aqueous solution $\left(0.1 \mathrm{M} \mathrm{Py}+0.1 \mathrm{M} \mathrm{LiClO}_{4}\right)$ under ultrasound irradiation, in silent conditions and on $950 \mathrm{rpm}$ rotating electrode $.1 \mathrm{~V} / \mathrm{SCE}$ for $100 \mathrm{~s}$ 

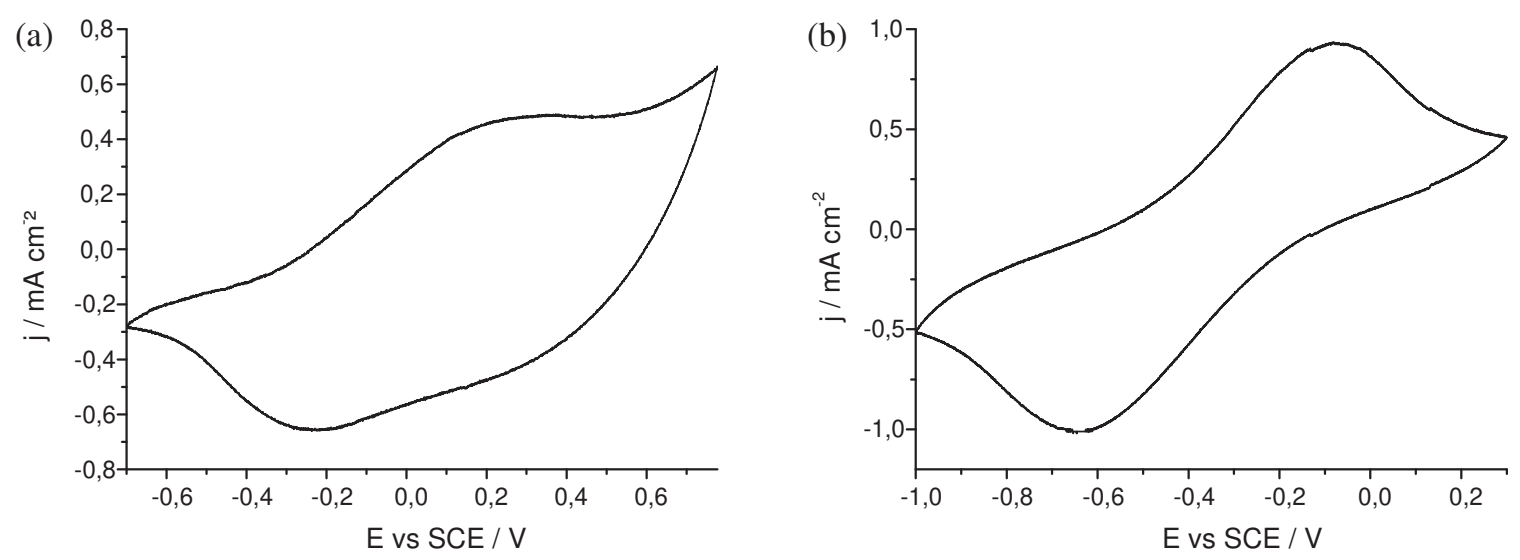

Fig. 4. Cyclovoltamograms of $10 \mu \mathrm{m}$ (a) $\mathrm{PPy}^{-\mathrm{ClO}_{4}}{ }^{-}$in $0.1 \mathrm{M} \mathrm{LiClO}_{4}$ aqueous solution and (b) PPy-TS ${ }^{-}$in $0.1 \mathrm{M} \mathrm{NaTS}$ aqueous solution. Scan rate $5 \mathrm{mV} / \mathrm{s}$.

characterization in previous works [27-30], this probably comes from a more compact structure of the film leading to more difficult movements for ions. Such increase in polymer compactness was also observed for low frequency sonicated PPy films [24].

For PPy/TS- (Fig. 6), in silent conditions reduction process seems no to be controlled either by diffusion or electron transfer alone but both phenomena are to be considered as $j_{p, c}$ is linear to $v$ and $\sqrt{v}$ $\left(R^{2}=0.9923\right.$ and 0.9956 respectively) at the same time. This mixed behavior for PPy/TS ${ }^{-}$was also observed in previous works [11]. When irradiated with ultrasound, this electrochemical behavior changes. The good linearity between $j_{p, c}$ and $\sqrt{v}$ is kept $\left(R^{2}=0.996\right)$
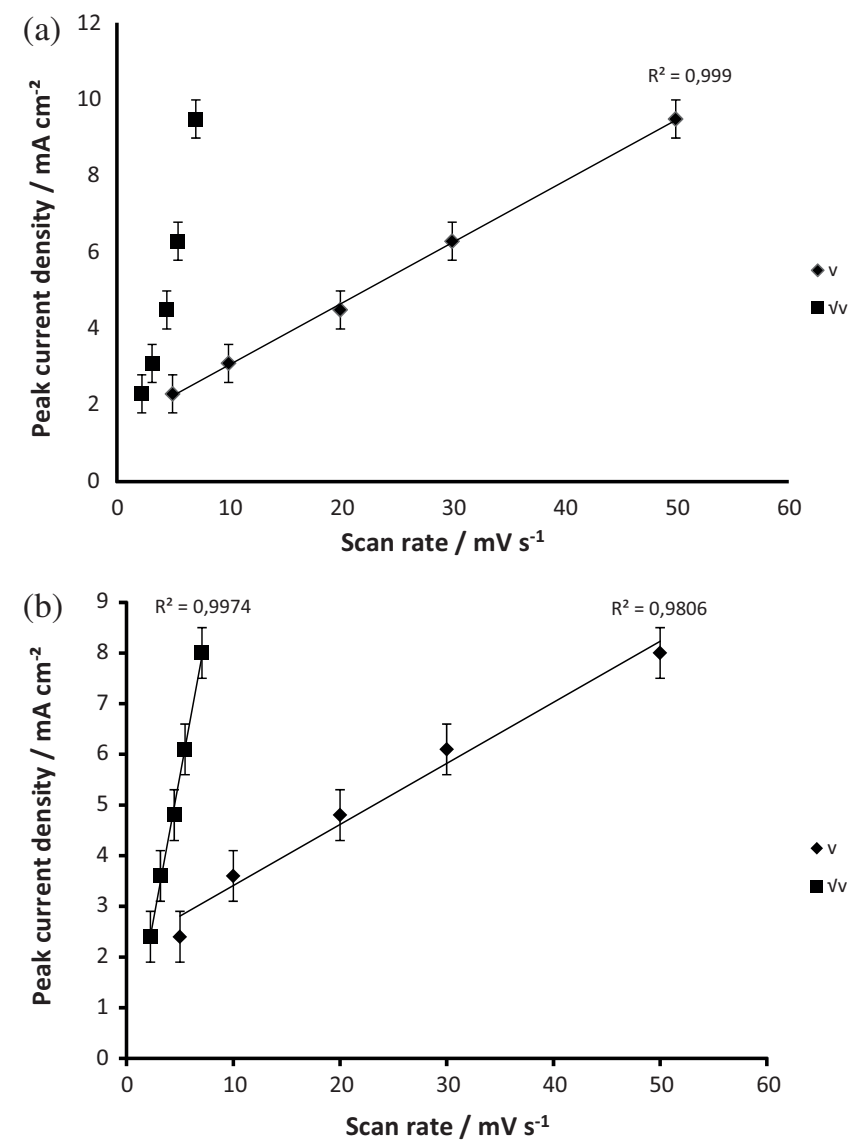

Fig. 5. Effect of scan rate $v$ on first reduction peak current density for $10 \mu \mathrm{m}$ $\mathrm{PPy} / \mathrm{ClO}_{4}{ }^{-}$electrosynthesized in aqueous solution $\left(0.1 \mathrm{M} \mathrm{Py}+0.1 \mathrm{M} \mathrm{LiClO}_{4}\right)(\mathrm{a})$ in silent conditions and (b) under ultrasound irradiation. The voltamograms were recorded in $0.1 \mathrm{M} \mathrm{LiClO}_{4}$ aqueous solution. while the one related to $v$ tends to disappear $\left(R^{2}=0.9691\right)$. As for $\mathrm{PPy} / \mathrm{ClO}_{4}{ }^{-}$case, this can be explained by more compact structure for sonicated PPy/TS- films. In confirmation with previous studies $[44,47]$, GDOES investigation (not reported) shows that the studied reduction peak was mainly due to insertion of $\mathrm{Na}^{+}$cations preferentially to expulsion of $\mathrm{TS}^{-}$anions, probably due to their big size and their strong interaction with pyrrole monomers for PPy which make their departure from the film difficult. Moreover, potential reduction peaks were always much more cathodic (at least $-300 \mathrm{mV}$ ) for sonicated films which reinforce the hypothesis of harder ions mobility within such films.
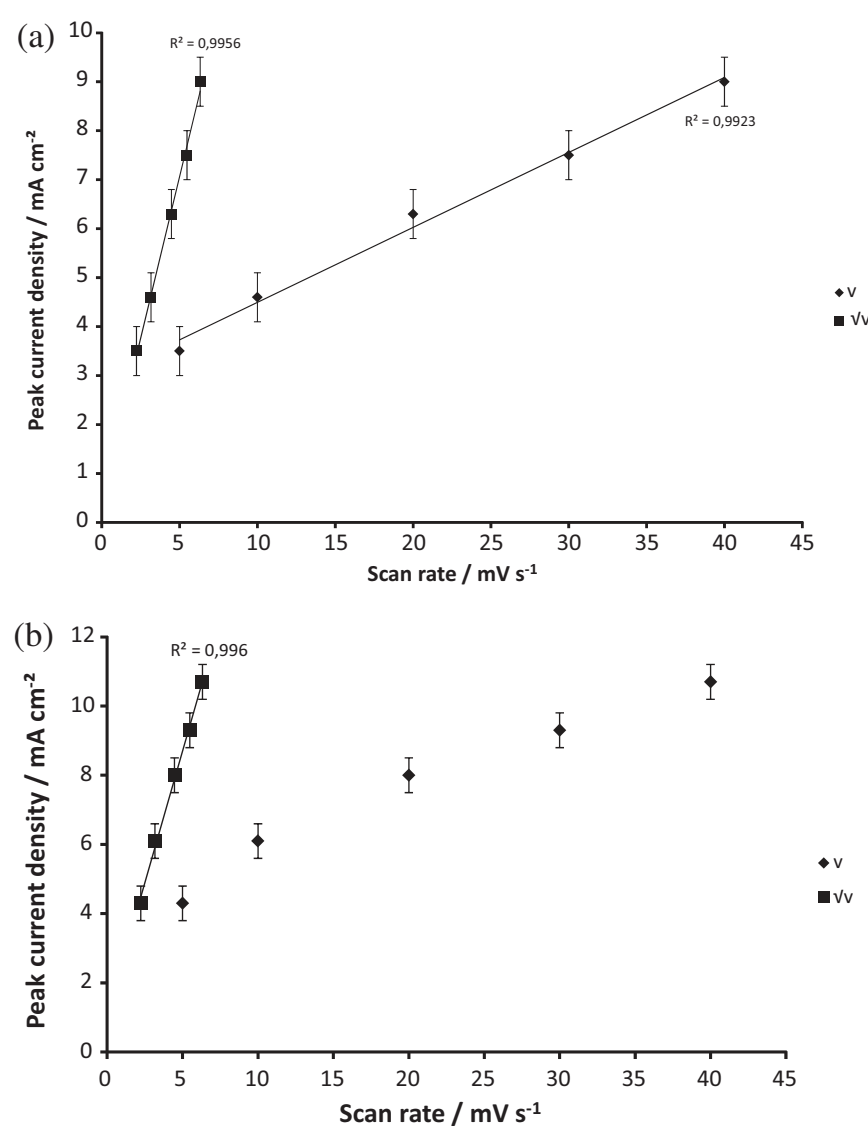

Fig. 6. Effect of scan rate $v$ on first reduction peak current density for $10 \mu \mathrm{m} \mathrm{PPy} / \mathrm{TS}^{-}$ electrosynthesized in aqueous solution $(0.1 \mathrm{M} P y+0.1 \mathrm{M} \mathrm{NaTS})(\mathrm{a})$ in silent conditions and (b) under ultrasound irradiation. The voltamograms were recorded in $0.1 \mathrm{M}$ NaTS aqueous solution. 


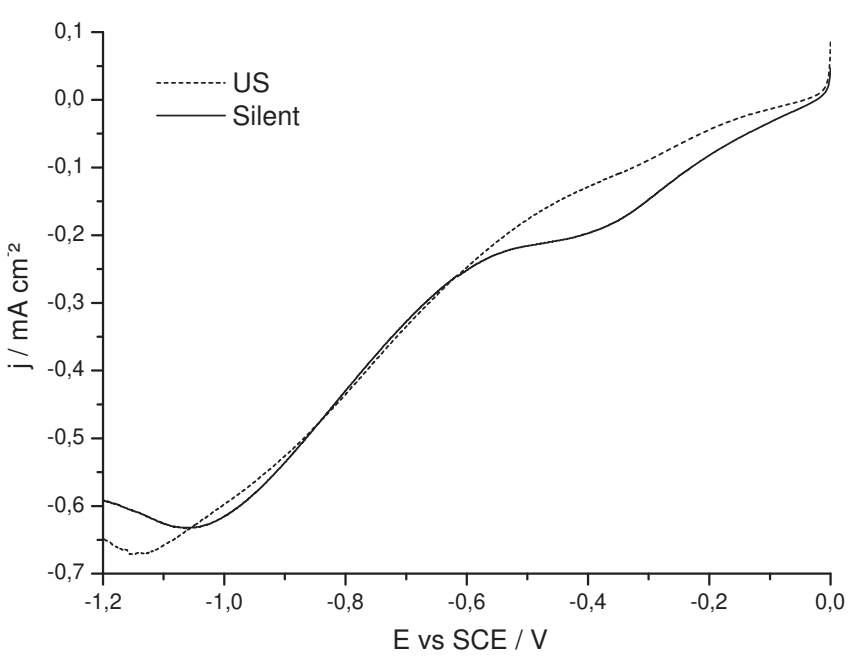

Fig. 7. Electrochemical dedoping of $2 \mu \mathrm{m} \mathrm{PPy} / \mathrm{MoO}_{4}{ }^{2-}$ electrosynthesized in aqueous solution $\left(0.2 \mathrm{M} \mathrm{Py}+5 \mathrm{mM} \mathrm{Na}_{2} \mathrm{MoO}_{4}\right)$ with and without ultrasound irradiation. The voltamograms were recorded in $5 \mathrm{mM} \mathrm{Na}_{2} \mathrm{MoO}_{4}$ aqueous solution at a scan rate of $5 \mathrm{mV} / \mathrm{s}$.

\subsection{Reduction processes of PPy/MoO ${ }_{4}^{2-}$ films}

Other experiments were realized in the presence of more original molybdate $\left(\mathrm{MoO}_{4}{ }^{2-}\right)$ anions. These species are commonly used as corrosion inhibitors for zinc protection. They also have been incorporated in PPy films to improve these films protection properties on zinc coated steel $[48,49]$. We found it interesting to study the behavior of such ions within PPy matrix. $2 \mu \mathrm{m}$ PPy was synthesized (with and without ultrasound) in $0.2 \mathrm{M} \mathrm{Py}+5 \mathrm{mM} \mathrm{Na}_{2} \mathrm{MoO}_{4}$. Such concentrations were chosen with respect to the ones used during elaboration on zinc for corrosion protection purposes. The lower thickness is due to low conductivity of the solution which made formation of thicker films difficult. The film was then immersed in $5 \mathrm{mM} \mathrm{Na}_{2} \mathrm{MoO}_{4}$ aqueous solution for electrochemical dedoping. The curve obtained for a scan rate of $5 \mathrm{mV} / \mathrm{s}$ is presented in Fig. 7. In silent conditions, two reduction peaks are visible at about $-350 \mathrm{mV}$ and $-1.05 \mathrm{~V} / \mathrm{SCE}$ proving the presence of two reduction processes. GDOES studies were carried out in order to investigate them; obtained profiles are reported in Fig. 8 and Fig. 9 for molybdene Mo and sodium Na elements, respectively. Fig. 8(a) shows an interesting repartition of Mo within non-sonicated film matrix. The film/substrate interface appears after about $60 \mathrm{~s}$ of sputtering. It seems that anions are preferentially located at film/air and film/electrode interfaces. It is known that PPy structure is more compact over the first tens of nanometers of deposit which would explain this higher concentration of $\mathrm{MoO}_{4}{ }^{2-}$ anions at the interface film/electrode as they cannot easily diffuse away. However, the reason these anions are also more concentrated at the film/air interface is not totally understood and this point is currently under study. This behavior is not present for films elaborated under ultrasound irradiation (Fig. 8b). Indeed, in this case $\mathrm{MoO}_{4}{ }^{2-}$ anions are more homogeneously distributed within the film. This is in accordance with more compact structure that would trap anions and prevent them from diffusing "freely" in the polymer matrix. Mo profiles were also realized just after the first reduction peak was achieved for non-sonicated films, as soon as cathodic polarization reached $-600 \mathrm{mV} / \mathrm{SCE}$ (Fig. 8a). One can see a decrease in Mo signal which implies the expulsion of $\mathrm{MoO}_{4}{ }^{2-}$ anions during this first reduction peak. The similar shape for Mo signal to the one of nonreduced film tends us to think of a uniform movement of anions all over PPy thickness. Same experiment was realized for sonicated films (Fig. 8b) and one can see that $\mathrm{MoO}_{4}{ }^{2-}$ anions do not seem
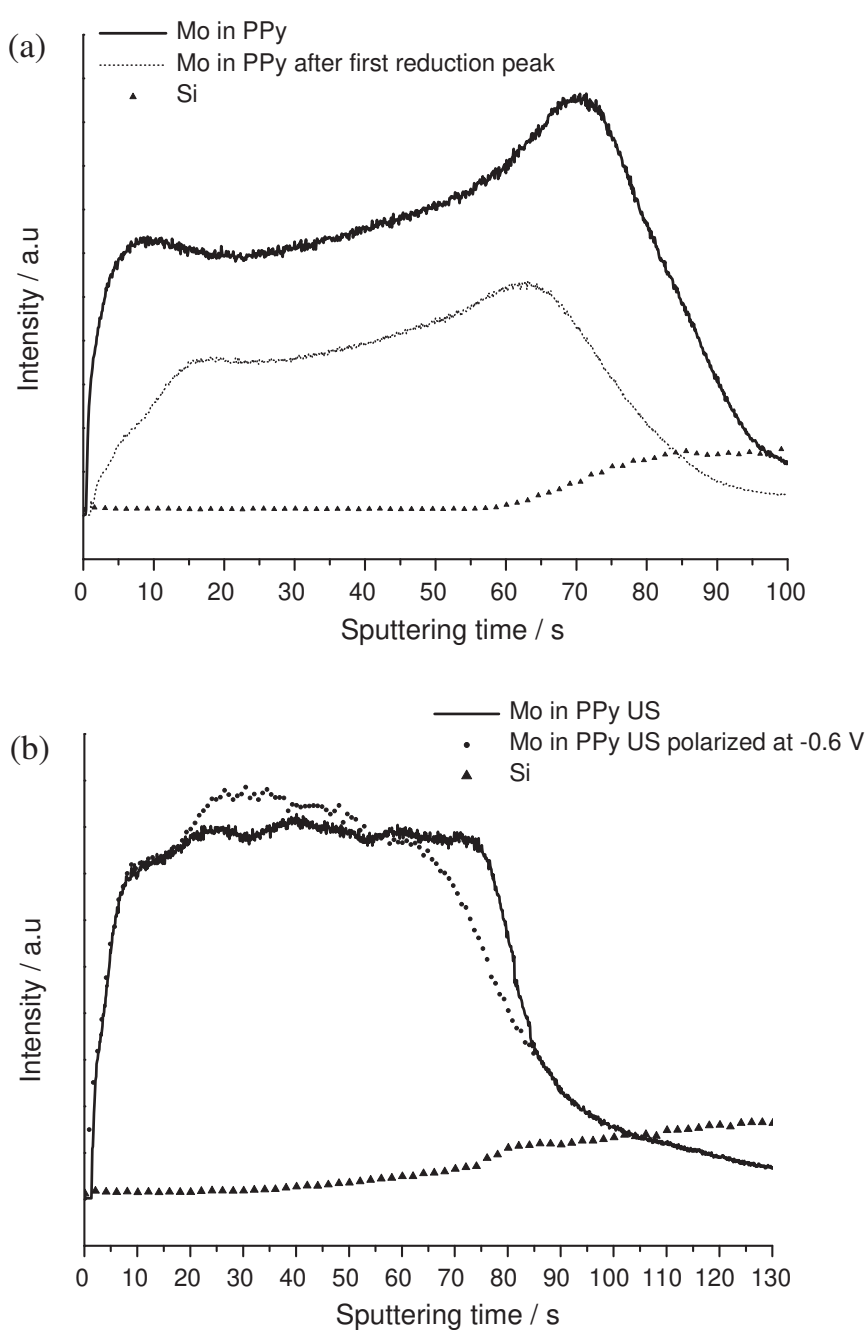

Fig. 8. Mo GDOES profiles obtained from $\mathrm{PPy} / \mathrm{MoO}_{4}{ }^{-}$films (a) in silent conditions and (b) under ultrasound irradiation. The profiles of such films after polarization from 0 to $-0.6 \mathrm{~V} / \mathrm{SCE}$ in $5 \mathrm{mM} \mathrm{Na}_{2} \mathrm{MoO}_{4}$ aqueous solution at a scan rate of $5 \mathrm{mV} / \mathrm{s}$ are also presented. $\mathrm{Si}$ is reported to situate the interface film/FTO electrode.

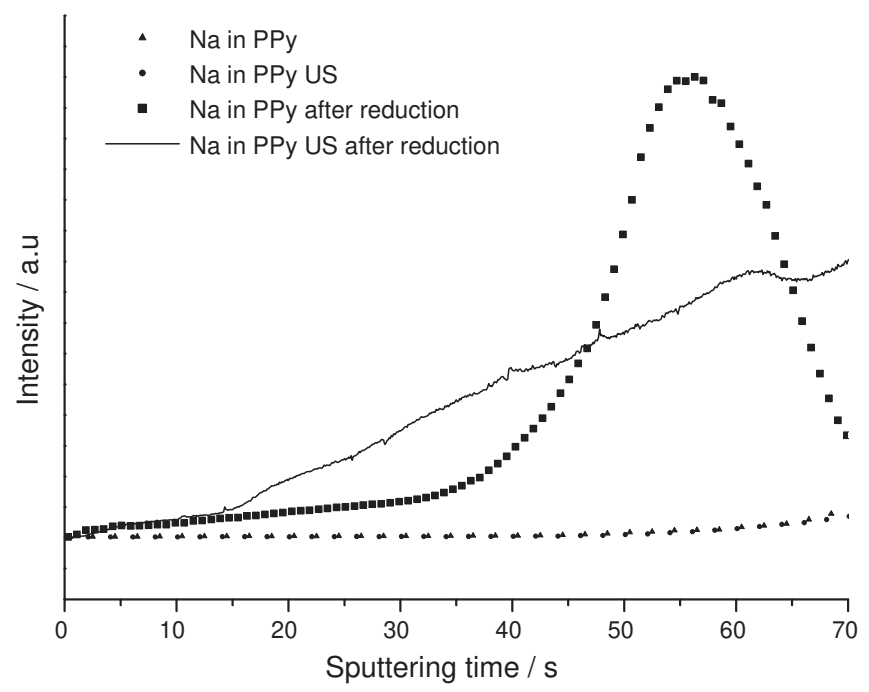

Fig. 9. $\mathrm{Na}$ GDOES profiles from $\mathrm{PPy} / \mathrm{MoO}_{4}{ }^{-}$films obtained in silent conditions and under ultrasound irradiation. The profiles of such films after reduction (up to $-1.2 \mathrm{~V} / \mathrm{SCE}$ ) in $5 \mathrm{mM} \mathrm{Na} \mathrm{MoO}_{4}$ aqueous solution at a scan rate of $5 \mathrm{mV} / \mathrm{s}$ are also presented. Si signal started to show after $70 \mathrm{~s}$ (not reported). 

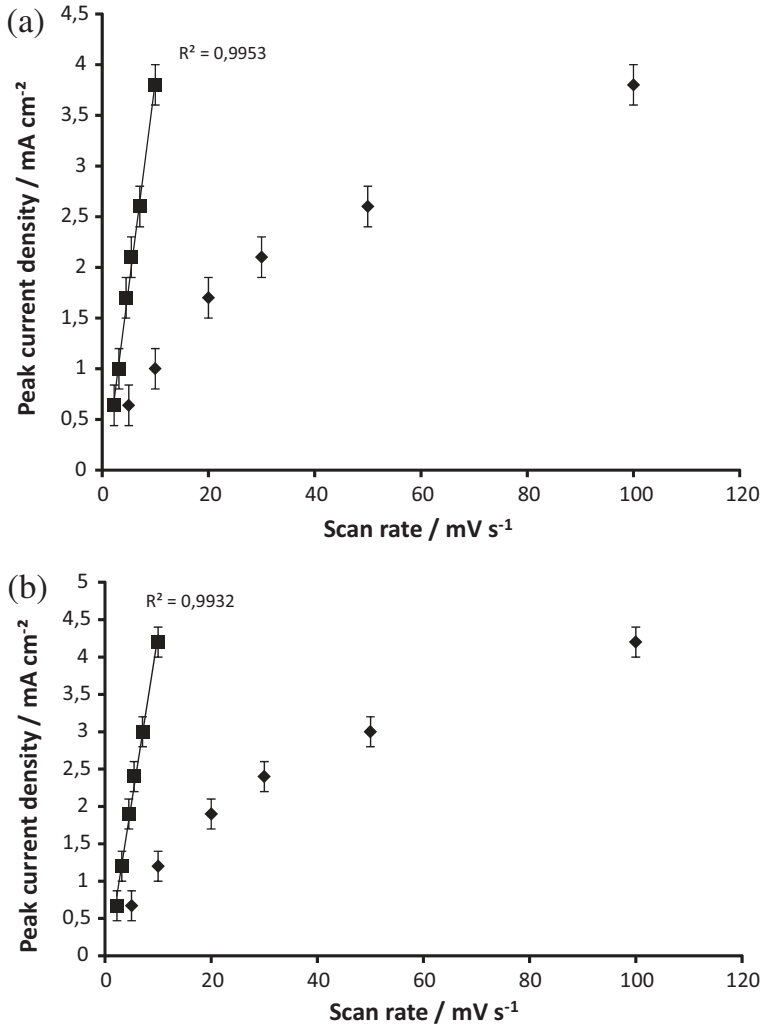

Fig. 10. Effect of scan rate $v$ on $\mathrm{Na}^{+}$insertion related reduction peak current density for $2 \mu \mathrm{m} \mathrm{PPy} / \mathrm{MoO}_{4}{ }^{-}$electrosynthesized in aqueous solution $(0.2 \mathrm{M} \mathrm{Py}+5 \mathrm{mM}$ $\left.\mathrm{Na}_{2} \mathrm{MoO}_{4}\right)(\mathrm{a})$ in silent conditions and (b) under ultrasound irradiation. Electrochemical dedoping was carried out in $5 \mathrm{mM} \mathrm{Na}_{2} \mathrm{MoO}_{4}$ aqueous solution.

to leave the film in this case, certainly due to much more compact structure. This is in accordance with the absence of a reduction peak around $-350 \mathrm{mV} / \mathrm{SCE}$.

The latter reduction peak is present for both PPy films (silent and sonicated). GDOES experiments were carried out after reaching of this peak in both cases and showed appearance of Na signal (Fig. 9). This shows that the second reduction process is insertion of $\mathrm{Na}^{+}$ cations in the film during reduction process to preserve electrical neutrality in the film. Here again, the repartition is not the same for silent and sonicated films. In the first case, the cations penetrated the films up to the film/electrode surface where they are mostly concentrated. For sonicated films, reparation of ions is wider as the more compact structure hampers their deep penetration and they cannot diffuse all the way to the film/electrode interface. The dependence of this latter peak current density $\left(j_{p, c}\right)$ with scan rate $v$ and square root of scan rate $\sqrt{v}$ was studied. Fig. 10 reports the results for silent and sonicated PPy films. In both cases, correlation of $j_{p, c}$ with $\sqrt{v}$ is linear since $R^{2}=0.993$ and 0.995 with and without ultrasound, respectively. It seems that reduction process is limited by diffusion of ions rather than charge transfer since evolution of $j_{p, c}$ is not linear to $v$. The shift of about $100 \mathrm{mV}$ towards cathodic potentials for sonicated PPy is in accordance with a more difficult $\mathrm{Na}^{+}$doping process in such films due to more compact structure.

\subsection{Doping level and conductivity of PPy}

XPS analyses were realized on previously studied sonicated and silent $\mathrm{PPy} / \mathrm{ClO}_{4}{ }^{-}$, $\mathrm{PPy} / \mathrm{TS}^{-}$and $\mathrm{PPy} / \mathrm{MoO}_{4}{ }^{2-}$ films to investigate elemental composition. In order to evaluate doping levels, N1s region was analyzed. It is noteworthy to remind that collected information only concern the extreme surface $(4-10 \mathrm{~nm})$. Fig. 11 reports results obtained for $\mathrm{PPy} / \mathrm{ClO}_{4}^{-}$films. The signal can be separated
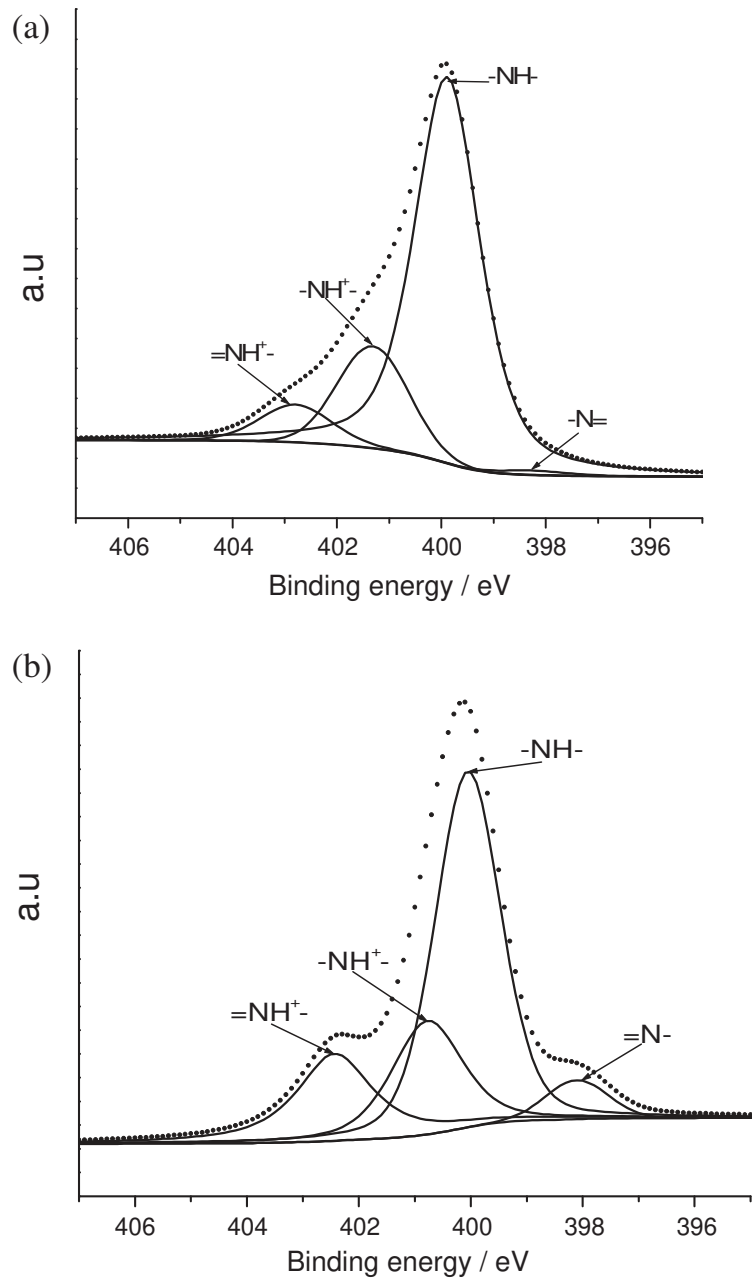

Fig. 11. N1s signal from XPS spectrum of $\mathrm{PPy} / \mathrm{ClO}_{4}{ }^{-}$film electrosynthesized in aqueous solution $\left(0.1 \mathrm{M} \mathrm{Py}+0.1 \mathrm{M} \mathrm{LiClO}_{4}\right)(\mathrm{a})$ in silent conditions and (b) under ultrasound irradiation.

into four components centered at 398.2, 399.9, 401.3 and $402.9 \mathrm{eV}$ for polypyrrole elaborated in silent conditions and at 398.0, 400.0, 400.8 and $402.5 \mathrm{eV}$ for the sample obtained under ultrasonication. These correspond to imine-like $(=\mathrm{N}-)$, amine-like $(-\mathrm{NH}-)$, polaron $\left(-\mathrm{NH}^{+}-\right)$and bipolaron $\left(=\mathrm{NH}^{+}-\right)$structures, respectively $[50,51]$. The ratio of charged components (polarons and bipolarons) signals with the entire nitrogen signal represents the doping level [50]. In silent conditions, it is of $24 \pm 2 \%$ while ultrasonication increases it up to $33 \pm 2 \%$. The bipolaron signal is especially increased by ultrasound irradiation. The reasons of such increase in doping level have been discussed in previous works [27].

XPS experiments realized on PPy/TS ${ }^{-}$and $\mathrm{PPy} / \mathrm{MoO}_{4}{ }^{2-}$ films (spectra not shown) confirm this behavior as an increase in doping level under ultrasound is maintained in all cases. For PPy/TS ${ }^{-}$ it varies from $27 \pm 2 \%$ in silent conditions to $33 \pm 2 \%$ for sonicated films. For PPy $/ \mathrm{MoO}_{4}{ }^{2-}$ the increase is not so big, as doping level is $28 \pm 2 \%$ without ultrasound and $30 \pm 2 \%$ with sonication.

Films conductivity was evaluated by widely used four-probe technique. Results are gathered in Table 1 . They are in total accordance with previous studies on non-sonicated $\mathrm{PPy} / \mathrm{ClO}_{4}{ }^{-}$and $\mathrm{PPy} / \mathrm{TS}^{-}$films [52]. Ultrasonication does not increase electrical conductivity of the films but on the opposite, a decrease is observed. It is not important for $\mathrm{PPy} / \mathrm{ClO}_{4}{ }^{-}$films but becomes higher for $\mathrm{PPy} / \mathrm{TS}^{-}$ and $\mathrm{PPy} / \mathrm{MoO}_{4}{ }^{2-}$. This observation is surprising for two reasons. The first one is related to studies carried out at low frequency. They reported an increase in conductivity for polythiophene or PPy 
Table 1

Electrical conductivity $\left(10^{4} \mathrm{~S} / \mathrm{m}\right)$ of different PPy films elaborated with and without ultrasound irradiation. Measurements were realized by four-probe technique.

\begin{tabular}{lccc}
\hline Electrical conductivity $\left(10^{4} \mathrm{~S} / \mathrm{m}\right)$ & $\mathrm{PPy} / \mathrm{ClO}_{4}{ }^{-}$ & $\mathrm{PPY} / \mathrm{TS}^{-}$ & $\mathrm{PPy} / \mathrm{MoO}_{4}{ }^{2-}$ \\
\hline Silent conditions & $0.3 \pm 0.1$ & $0.7 \pm 0.1$ & $3.2 \pm 0.1$ \\
US & $0.2 \pm 0.1$ & $0.2 \pm 0.1$ & $2.7 \pm 0.1$
\end{tabular}

electrosynthesized under low frequency ultrasonication [20,21,23]. No reason made us think it would be different for high frequencies before experimental observations. The second one is about the increase in doping level previously observed which would tempt us to think that an increase in electrical conductivity is obvious. Moreover, higher compactness for sonicated films would also be in favor of highest conductivity.

From our point of view, this decrease in conductivity can come from two different phenomena. It could be assigned to breakage of polymer chains due to cavitation bubbles implosion releasing big amounts of energy, high enough to damage PPy molecular structure. Such shorter chains must result in conductivity decrease as electronic conjugation lengths would be reduced. This was already assumed by Yang and Li for electrosynthesis of PPy under high intensity ( $>50 \mathrm{~W}$ ) low frequency ultrasound [20]. Another explanation would come from presence of hydroxyl radicals $(\mathrm{OH} \cdot)$ generated by water sonolysis during ultrasonication. When immersing PPy in solution containing such oxidative radicals for $2 \mathrm{~h}$, high destructive effects occur on PPy resulting in overoxidation and destruction of its electroactivity [53]. During electrosynthesis, such radical species could also be harmful for PPy by reacting with active radical centers of growing $\mathrm{PPy}$. $\mathrm{OH}$ and $\mathrm{C}=\mathrm{O}$ groups could thus be incorporated in the polymer resulting in structure changes, conjugation rupture and shorter chains. These radicals can be quantified in the sonicated solution by several techniques such as terephthalate, iodide or Fricke dosimetry [54]. This last one has been chosen for its simplicity and wide use in sonochemistry. It permits quantification of oxidative species such as radicals and $\mathrm{H}_{2} \mathrm{O}_{2}$ created by solvent sonolysis. For our sonoreactor, concentrations were below $0.1 \mathrm{mM}$ for considered irradiation time (<30 min).

Effects of hydroxyl radicals during electrosynthesis of PPy were studied. In order to do so, these radicals were chemically generated using Fenton's reagent, a mixture of hydrogen peroxide and ferrous ions. The following reaction occurs:

$\mathrm{H}_{2} \mathrm{O}_{2}+\mathrm{Fe}^{2+} \rightarrow \mathrm{OH}^{\bullet}+\mathrm{OH}^{-}+\mathrm{Fe}^{3+}$

This reaction is propagated by $\mathrm{Fe}^{2+}$ regeneration, mainly due to reduction of $\mathrm{Fe}^{3+}$ by $\mathrm{H}_{2} \mathrm{O}_{2}$.

Concentration in $\mathrm{H}_{2} \mathrm{O}_{2}$ (1 mM) has been chosen in our case in order to widely work in the same order of concentration in hydroxyl radicals that under ultrasound irradiation. However, it is very difficult to perfectly know such radicals' concentration due to their high instability and the point being to study their effects during electrosynthesis on PPy conductivity, the made approximations are sufficient. Electropolymerization of Py was realized at $1 \mathrm{~V} / \mathrm{SCE}$ in $\left(0.1 \mathrm{M} \mathrm{Py}+0.1 \mathrm{M} \mathrm{LiClO}_{4}+10^{-3} \mathrm{M} \mathrm{Fe}^{2+}\right)$ and also in the same middle $+1 \mathrm{mM} \mathrm{H}_{2} \mathrm{O}_{2}$ to generate hydroxyl radicals via reaction (1). In both cases film conductivity was $0.3 \pm 0.1 \times 10^{4} \mathrm{~S} / \mathrm{m}$, the same conductivity as $\mathrm{PPy} / \mathrm{ClO}_{4}{ }^{-}$films: the presence of $\mathrm{Fe}^{2+}$ in polymerization solution seems to not have any influence on film conductivity. More importantly, presence of hydroxyl radicals during electrosynthesis does not decrease film conductivity but no effect is seen. XPS characterization of the films (spectra not reported) are in accordance with this, as no difference was evidenced for $\mathrm{C} 1 \mathrm{~s}$ region while film usual overoxidation lets appear an increase in $\mathrm{C}=\mathrm{O}$ signal $[55,56]$. The most probable reason which would explain such behavior is a concentration in hydroxyl radicals too low to modify film chemical structure and therefore no harmful effect on film conductivity is to be seen. To make sure it is a matter of concentration; PPy was electrosynthesized in the same previous conditions but with a concentration in $\mathrm{H}_{2} \mathrm{O}_{2}$ brought up to $2 \mathrm{M}$ to highly increase the amount of generated hydroxyl radicals. The obtained films' conductivity decreased down to $30 \mathrm{~S} / \mathrm{m}$.

Therefore, it seems clearer that the observed decrease in conductivity for sonicated PPy might not be due to reaction of sonolysis generated hydroxyl radicals that would react with the growing film (because of too low concentration), but more to cavitation effects damaging polymer chains. Such degradation effects were already assumed for electropolymerization under low frequency ultrasound [20,21]. Kojima et al. also showed a degradation of polymer chains due to ultrasonic cavitation activity for chemically polymerized styrene [57]. Evaluation of polymerization degree would provide very useful information but unfortunately PPy is insoluble in most organic solvent which makes this kind of experiment impossible. However, this damaging effect must not be predominant as sonicated PPy still exhibits good electrical conductivity, not very far from silent films.

\section{Conclusions}

This work explored effects of high frequency ultrasound on PPy electrosynthesis. Mass transfer enhancement has been evidenced by chronoamperometry. Since first stages of deposition, ultrasound leads to higher number of growth centers leading eventually to thinner and more homogeneous surface structure for thick deposits. Ultrasound is thus useful to control surface structure properties of such films.

Much more compact structure for sonicated films is likely to be the cause of change in rate-determining steps during PPy reduction process. Very interesting ion-sieving behavior was attributed for PPy $/ \mathrm{MoO}_{4}{ }^{2-}$ films elaborated under ultrasound. Unique electrochemical properties and ions repartition within polymer matrix were assigned to these films, thanks to very dense structure.

Finally, films doping level and conductivity characteristics were investigated. Sonicated PPy was shown to have higher doping level than the one elaborated in silent conditions. Strangely, ultrasound leads to decrease in electrical conductivity probably due to partial degradation of polymer chains by cavitation effects.

\section{References}

[1] C.D. Dimitrakopoulos, P.R.L. Malenfant, Adv. Mater. 14 (2002) 99

[2] G. Horowitz, Adv. Mater. 10 (1998) 365.

[3] A. Kraft, A.C. Grimsdale, A.B. Holmes, Angew. Chem. Int. Ed. 37 (1998) 402

[4] W.U. Huynh, J.J. Dittmer, A.P. Alivisatos, Science 295 (2002) 2425

[5] G. Yu, J. Gao, J.C. Hummelen, F. Wudl, A.J. Heeger, Science 270 (1995) 1789.

[6] S.U. Rahman, M.A. Abul-Hamayel, B.J. Abdul Allem, Surf. Coat. Technol. 200 (2006) 2948

[7] C.M. Li, C.Q. Sun, W. Chen, L. Pan, Surf. Coat. Technol. 198 (2005) 474.

[8] U. Lange, N.V. Roznyatovskaya, V.M. Mirsky, Anal. Chim. Acta 614 (2008) 1.

[9] B. Lakard, O. Segut, S. Lakard, G. Herlem, T. Gharbi, Sens. Actuators B 122 (2007) 101.

[10] A. Et Taouil, F. Lallemand, J.M. Melot, J. Husson, J.Y. Hihn, B. Lakard, Synth. Met. 160 (2010) 1073.

[11] D.A. Kaplin, S. Qutubuddin, Polymer 36 (1995) 1275.

[12] T. Patois, B. Lakard, N. Martin, P. Fievet, Synth. Met. 160 (2010) 2180.

[13] I. Mogi, K. Watanabe, M. Motokawa, J. Electroanal. Chem. 507 (2001) 198.

[14] M.S. Cho, Y.Y. Yun, J.D. Nam, Y. Son, Y. Lee, Synth. Met. 158 (2008) 1043.

[15] M. Atobe, A. Murotani, S. Hitose, Y. Suda, M. Sekido, T. Fuchigami, et al., Electrochim. Acta 50 (2004) 977.

[16] M.L. Doche, J.Y. Hihn, F. Touyeras, J.P. Lorimer, T.J. Mason, M. Plattes, Ultrason Sonochem. 8 (2001) 291.

[17] R.G. Compton, J.C. Eklund, S.D. Page, G.H.W. Sanders, J. Booth, J. Phys. Chem. 98 (1994) 12410.

[18] B.G. Pollet, J.Y. Hihn, M.L. Doche, J.P. Lorimer, A. Mandroyan, T.J. Mason, J. Electrochem. Soc. 154 (10) (2007) E131.

[19] C. Petrier, A. Jeunet, J.L. Luche, G. Reverdy, J. Am. Chem. Soc. 114 (1992) 3148.

[20] J. Yang, Y. Li, Chin. J. Polym. Sci. 14 (1996) 270.

[21] S. Osawa, M. Ito, K. Tanaka, J. Kuwano, Synth. Met. 18 (1987) 145. 
[22] M. Atobe, T. Kaburagi, T. Nonakara, D. Kagaku, Electrochemistry 67 (12) (1999) 1114.

23] S. Osawa, M. Ito, K. Tanaka, J. Kuwano, J. Polym. Sci. 30 (1992) 19

[24] M. Atobe, H. Tsuji, R. Asami, T. Fuchigami, J. Electrochem. Soc. 153 (1) (2006) D10.

[25] J. Klima, C. Bernard, J. Electroanal. Chem. 462 (1999) 181.

[26] T.J. Mason, J.P. Lorimer, D.M. Bates, Ultrasonics 30 (1992) 40.

[27] A. Et Taouil, F. Lallemand, J-Y. Hihn, J.M. Melot, V. Blondeau-Patissier, B. Lakard, Ultrason. Sonochem. 18 (2011) 140.

[28] A. Et Taouil, F. Lallemand, L. Hallez, J.Y. Hihn, Electrochim. Acta 55 (28) (2010) 9137.

[29] J. Dejeu, A. Et Taouil, P. Rougeot, S. Lakard, F. Lallemand, B. Lakard, Synth. Met. 160 (2010) 2440.

[30] A. Et Taouil, F. Lallemand, J-Y. Hihn, V. Blondeau-Patissier, Ultrason. Sonochem. 18 (2011) 907.

[31] A.J. Downard, D. Pletcher, J. Electroanal. Chem. 206 (1986) 139.

[32] F.A. Harraza, J. Electrochem. Soc. 153 (2006) C349.

[33] A.F. Diaz, J.I. Castillo, J.A. Logan, W.J. Lee, J. Electroanal. Chem. 129 (1981) 115.

[34] J.J. Lopez Cascales, T.F. Otero, J. Chem. Phys. 120 (2004) 1951.

[35] J.I. Martins, T.C. Reis, M. Bazzaoui, E.A. Bazzaoui, L. Martins, Corr. Sci. 46 (2004) 2361.

[36] D. Kowalski, M. Ueda, T. Ohtsuka, Corr. Sci. 50 (2008) 286.

[37] R. Asami, M. Atobe, T. Fuchigami, J. Am. Chem. Soc. 127 (2005) 13160.

[38] R. Asami, T. Fuchigami, M. Atobe, Langmuir 22 (2006) 10258.
[39] M. Atobe, S. Ikari, K. Nakabayashi, F. Amemiya, T. Fuchigami, Langmuir 26 (2010) 9111

[40] E.L. Kupila, J. Lukkari, J. Kankare, Synth. Met. 74 (1995) 207.

[41] U. Johanson, A. Marandi, T. Tamm, J. Tamm, Electrochim. Acta 50 (2005) 1523.

[42] M.D. Levi, C. Lopez, E. Vieil, M.A. Vorotyntsev, Electrochim. Acta 42 (1997) 757.

[43] G. Inzelt, V. Kertesz, A.S. Nyback, J. Solid State Electrochem. 3 (1999) 251.

[44] V. Syritski, A. Opik, O. Forsen, Electrochim. Acta 48 (2003) 1409.

[45] E. Vieil, C. Lopez, J. Electroanal. Chem. 466 (1999) 218.

[46] Y. Li, Electrochim. Acta 42 (1997) 203.

[47] T. Raudsepp, M. Marandi, T. Tamm, V. Sammelselg, J. Tamm, Electrochim. Acta 53 (2008) 3828.

[48] S. Tsuchiya, M. Ueda, T. Ohtsuka, Isij Int. 47 (2007) 151.

[49] G. Paliwoda-Porebska, M. Rohwerder, M. Stratmann, U. Rammelt, L.M. Duc, W. Plieth, J. Solid State Electrochem. 10 (2006) 730

[50] J. Petitjean, S. Aeiyach, J.C. Lacroix, P.C. Lacaze, J. Electroanal. Chem. 478 (1999) 92.

[51] F. Lallemand, D. Auguste, C. Amato, L. Hevesi, J. Delhalle, Z. Mekhalif, Electrochim. Acta 52 (2007) 4334.

[52] J. Ouyang, Y. Li, Polymer 38 (1997) 1971.

[53] C. Debiemme-Chouvy, T.T.M. Tran, Electrochem. Commun. 10 (2008) 947.

[54] Y. Iida, K. Yasui, T. Tuziuti, M. Sivakumar, Microchem. J. 80 (2005) 159.

[55] H. Ge, G. Qi, Polymer 35 (1994) 504

[56] C. Malitesta, I. Losito, L. Sabbatini, P.G. Zambonin, J. Electron. Spectrosc. Relat. Phenom. 76 (1995) 629.

[57] Y. Kojima, S. Koda, H. Nomura, Ultrason. Sonochem. 8 (2001) 75. 